\title{
BMJ Open GP retention in the UK: a worsening crisis. Findings from a cross-sectional
} survey

\author{
Katherine Owen, Thomas Hopkins, Thomas Shortland, Jeremy Dale
}

To cite: Owen K, Hopkins T, Shortland T, et al. GP retention in the UK: a worsening crisis. Findings from a crosssectional survey. BMJ Open 2019;9:e026048. doi:10.1136/ bmjopen-2018-026048

- Prepublication history and additional material for this paper are available online. To view these files, please visit the journal online (http://dx.doi. org/10.1136/bmjopen-2017026048).

Received 14 August 2018 Revised 10 December 2018 Accepted 28 January 2019

Check for updates

(C) Author(s) (or their employer(s)) 2019. Re-use permitted under CC BY-NC. No commercial re-use. See rights and permissions. Published by BMJ.

Division of Health Sciences, Warwick Medical School, Coventry, UK

Correspondence to Professor Jeremy Dale; jeremy.dale@warwick.ac.uk

\section{ABSTRACT}

Objective To investigate how recent national policy-led workforce interventions are affecting intentions to remain working as a general practitioner (GP).

Design Online questionnaire survey with qualitative and quantitative questions.

Setting and participants All GPs (1697) in Wessex region, an area in England for which previous GP career intention data from 2014 is available.

Results 929 (54.7\%) participated. 59.4\% reported that morale had reduced over the past two years, and $48.5 \%$ said they had brought forward their plans to leave general practice. Intention to leave/retire in the next 2 years increased from $13 \%$ in the 2014 survey to $18 \%$ in October/November 2017 ( $p=0.02)$, while intention to continue working for at least the next 5 years dropped from $63.9 \%$ to $48.5 \%$ ( $p<0.0001)$. Age, length of service and lower job satisfaction were associated with intention to leave. Work intensity and amount were the most common reasons given for intention to leave sooner than previously planned; $51.0 \%$ participants reported working more hours than 2 years previously, predominantly due to increased workload. GPs suggested increased funding, more GPs, better education of the public and expanding non-clinical and support staff as interventions to improve GP retention. National initiatives that aligned with these priorities, such as funding to expand practice nursing were viewed positively, but low numbers of GPs had seen evidence of their roll-out. Conversely, national initiatives that did not align, such as video consulting, were viewed negatively.

Conclusion While recent initiatives may be having an impact on targeted areas, most GPs are experiencing little effect. This may be contributing to further lowering of morale and bringing forward intentions to leave. More urgent action appears to be needed to stem the growing workforce crisis.

\section{INTRODUCTION}

The general practice workforce in England has been recognised as being at crisis point for several years. ${ }^{1-3}$ Despite a government commitment in 2015 to create 5000 additional general practitioner (GP) posts by $2020,{ }^{4}$ recent figures suggest that a further deficit of 1300 full-time equivalent GPs has developed. ${ }^{5}$ This shortfall reflects a pattern of falling recruitment to GP specialist training ${ }^{6}$

\section{Strengths and limitations of this study}

- This is the first survey to report general practitioners (GPs) views and experience of national initiatives which have been introduced in England to address the workforce crisis in general practice.

- The survey was conducted in the same region as a similar survey in 2014, so allowing some analysis of how views are changing over time.

- The response rate was reasonable for this type of survey.

- The free-text qualitative data added depth to the findings.

and increasing numbers of GPs leaving to work abroad, take career breaks, work part time or retire early. ${ }^{7-9}$ While recruitment to GP training improved in 2017 with the highest ever number of trainees appointed, concerns over retention remain. Factors that are implicated include intensity of workload, administrative burden, lack of recognition of the value of general practice and fear of litigation. ${ }^{6} 8$ 10-13 Moving towards an increasingly mixed workforce using allied health professionals has been proposed, ${ }^{14}$ although it has been suggested that unintended consequences may be reduced continuity of care, substitution rather than supplementation and increased costs. ${ }^{15}$

In 2014, a survey of the GP workforce in Wessex (a region in the South of England with a population of 2.1 million) completed by 1398 participants found that $14 \%$ were planning to retire in the next 2 years, a further $4 \%$ were planning a career change and $20 \%$ were planning to retire earlier than planned $^{16}$ (box 1).

This pattern is similar to that reported in other surveys that also found high rates of intention to leave practice in the next 5 years; namely, the West Midlands $(41 \%)^{8}$ and South West of England $(37 \%) .{ }^{7}$ Low morale appears to be the primary driver to intention to quit ${ }^{7}$ with underlying factors related to workload 


\section{Box 1 Wessex LMC Survey 2014: key findings ${ }^{16}$}

A total of $1398 \mathrm{GPs}$ responded: $77.4 \%$ practice partners, $14.0 \%$ salaried GPs $8.6 \%$ locum GPs.

Intention to retire: $31.8 \%$ planned to retire/leave general practice within 5 years.

Intention to change hours worked: $69.3 \%$ wanted to stay the same, $2.7 \%$ wanted to increase, $21.5 \%$ wanted to decrease and $6.5 \%$ wanted to take on other work.

volume and intensity ${ }^{8}$, concerns regarding fear and risk, uncertainty and feeling undervalued. ${ }^{10}$

This study was undertaken in Wessex to explore how attitudes and intentions have changed in light of new national policy-led initiatives ${ }^{4}$ to improve the workforce situation for GPs, and to gain views about what is needed to improve the current workforce situation.

\section{METHODS}

A questionnaire including qualitative and free-text elements was designed incorporating questions asked in the initial Wessex survey ${ }^{16}$ relating to future intentions regarding GP work, intention to retire and reasons for those planning early retirement. It included demographic questions relating to the age, sex, and employment and training history with questions were added to explore reasons for intended change in hours worked, job satisfaction and morale, and experience of recent local and national initiatives designed to improve GP retention and workload. Most questions had tick box answers for ease of completion. In addition, there were some open questions to encourage free-text expression of views. The survey (see online supplementary file 1) was piloted for comprehensibility with GPs working outside the area.

As the Health Education England regional appraisal team has the most complete list of GPs who are registered to practise in the area, they agreed to use their database to send an invitation to participate to all eligible GPs. This did not include training grade GPs, but included retired GPs who have chosen to retain a licence to practise. The invitations were sent by email and included an online link to the questionnaire which was held on Survey Monkey. Two reminders were sent at 2-3 weekly intervals in October and November 2017.

Due to privacy restrictions, we were unable to access the original data from the 2014 survey and so were limited to using publicly information ${ }^{1}$ for making comparisons with data from the current survey.

\section{Qualitative analysis}

Included in the survey were two open questions; 'What is the greatest problem within general practice at the current time' and 'What intervention would help general practice the most?'. The free-text comments were imported into NVivo V.11 and analysed with a thematic approach. ${ }^{17}$ Following a period of familiarisation, TS and TH developed an initial coding framework by coding a subset of 100 of the comments independently. This was reviewed by the full research team, and the agreed coding framework was then applied to the free-test data. The higher order categories were linked to the quantitative analysis in order to supplement and expand the interpretation of the data, and illustrative quotes were selected.

\section{Quantitative analysis}

Basic descriptive statistics were used to characterise the survey population and compare it to Health Education England data. ${ }^{5}$ Binary logistic regression analysis was employed to identify predictors of GPs' intentions to retire within 5 years using a range of covariates, which were entered into the model simultaneously; gender, age, hours of work, role, length of service, job satisfaction.

Participants were provided with an information sheet outlining the study and were informed that completion of the online questionnaire would be taken as consent to participate.

\section{Patient and public involvement}

Patient and public involvement was not included in this study. The research question, although important to patients and the public, was focused on professional and health service priorities and experiences.

\section{RESULTS}

\section{Participants}

The survey was distributed by email to the 1697 GPs listed as working in Wessex, leading to $929(54.7 \%)$ respondents. Of these, $509(54.8 \%)$ were female, the modal age was $45-55$ years $(n=253,32.9 \%)$ and most had been trained in the UK (93.0\%). When compared with National Health Service (NHS) demographic data for all GPs in Wessex, there was no difference in gender balance, but there was a difference in age distribution, with our survey having an over-representation of older GPs $(28.4 \%$ aged greater than 55 years compared with $20.1 \%$ in the NHS data; $\left.\chi^{2}=20.6, \mathrm{p}<0.001\right)$.

When compared with the 2014 survey respondents, the current survey included more older GPs $(28.4 \%$ aged greater than 55 years, compared with $23.7 \%$ previously) and more who were working in non-principal roles ( $41.5 \%$ compare to $22.6 \%$ previously), see table 1 .

Nearly half of the respondents had spent over 20 years in general practice; one-third reported working over 41 hours per week; and nearly two-thirds reported having at least one additional employed role in addition to their NHS GP clinical responsibilities.

The two open questions had high completion rates $(\mathrm{n}=807,86.9 \% ; \mathrm{n}=819,88.2 \%$, respectively), and the answers together provided a dataset of 29679 free-text words; individual responses ranging from 1 to 340 words $($ mean $=18)$. 


\begin{tabular}{|c|c|c|}
\hline & $2017(\%)$ & 2014 (\%) \\
\hline \multicolumn{3}{|l|}{ Age } \\
\hline $25-34$ & $64(8.3)$ & $117(8.5)$ \\
\hline $35-44$ & $233(30.3)$ & $398(29.0)$ \\
\hline $45-54$ & $253(32.9)$ & $533(38.8)$ \\
\hline $55-64$ & $204(26.6)$ & $313(22.8)$ \\
\hline $65+$ & $14(1.8)$ & $13(0.9)$ \\
\hline Missing & 161 & 24 \\
\hline \multicolumn{3}{|l|}{$\chi^{2}=11.9, p<0.02$} \\
\hline \multicolumn{3}{|l|}{ Role } \\
\hline General practice principal & $531(58.5)$ & $1082(77.4)$ \\
\hline Salaried GP & $218(24.0)$ & $196(14.0)$ \\
\hline Locum GP & $141(15.6)$ & $120(8.6)$ \\
\hline Out of hours GP & $17(1.9)$ & - \\
\hline Missing & 22 & - \\
\hline$\chi^{2}=82.3, p<0.0001$ & & \\
\hline
\end{tabular}

\section{Changes in work volume, intensity and morale}

Respondents reported working an average of 29.6 hours a week (range 1-66) of which an average of 20.1 hours (range 2-59) were in direct contact with patients. As shown in table 2, the number of hours worked varied by employment status, with almost half of GP principals working 41 hours or more per week, while the most salaried GPs worked fewer than 30 hours per week and the majority of locum GPs worked fewer than 20 hours.

Comparing current workload with 2 years previously, $51.0 \%$ (470) reported working longer hours with almost all $(94.4 \%$; 423$)$ giving increased workload as the predominant reason; $26.6 \%$ had reduced their hours of work, with most $(72.3 \%$; 172$)$ stating this was due to increasing intensity of workload and for many $(29.8 \%$; 71$)$ it was related to stress and mental health. This contrasts with the intentions stated in the previous survey where $21.5 \%$ of GPs wished to reduce their hours worked and only $2.7 \%$ wished to increase.

Morale was reported as having reduced over the past 2 years for $59.4 \%$ (510) of respondents and increased for

Table 2 Hours worked in general practice (GP) according to employment status

\begin{tabular}{lclll}
\hline $\begin{array}{l}\text { Hours } \\
\text { worked }\end{array}$ & $\begin{array}{l}\text { GP principal } \\
\text { (\%) }\end{array}$ & $\begin{array}{l}\text { Salaried } \\
\text { GP (\%) }\end{array}$ & $\begin{array}{l}\text { Locum GP } \\
(\%)\end{array}$ & $\begin{array}{l}\text { Out of } \\
\text { hours GP } \\
(\%)\end{array}$ \\
\hline Up to 10 & $3(0.6)$ & $10(4.7)$ & $32(25.8)$ & $4(57.1)$ \\
\hline $11-20$ & $12(2.3)$ & $43(20.4)$ & $37(29.8)$ & $3(42.9)$ \\
\hline $21-30$ & $82(15.6)$ & $68(32.2)$ & $35(28.2)$ & $0(0.0)$ \\
\hline $31-40$ & $179(34.0)$ & $57(27.0)$ & $14(11.3)$ & $0(0.0)$ \\
\hline 41 or more & $250(47.5)$ & $33(15.6)$ & $6(4.8)$ & $0(0.0)$ \\
\hline
\end{tabular}

Table 3 Length of time to when general practice intended leave/retire from general practice

\begin{tabular}{lcc} 
& 2014 & 2017 \\
\hline Less than 1 year & $93(6.7)$ & $72(8.4)$ \\
1-2 years & $92(6.7)$ & $84(9.8)$ \\
2-5years & $254(18.4)$ & $205(23.9)$ \\
5+ years & $883(63.9)$ & $416(48.5)$ \\
Unsure/other & $59(4.3)$ & $81(9.4)$ \\
$\chi^{2}=37.2, p<0.0001$ & & \\
\hline
\end{tabular}

$14.1 \%$ (121). In total, $28.9 \%$ (247) now reported having positive morale and $42.7 \%$ (365) negative morale.

\section{Intention to leave GP}

When asked to think about their career plans compared with 2years ago, $409(48.5 \%)$ said they had brought forward their plans to leave GP, with just 47 (5.6\%) planning to remain longer. Intention to leave/retire in the next 2 years has increased from $13 \%$ in 2014 to $18 \%$ $(\mathrm{p}=0.02)$, while $63.9 \%$ reported an intention to continue working for at least the next 5 years in 2014 compared with only $48.5 \%$ in 2017 ( $\mathrm{p}<0.0001)$ (see table 3$)$.

Binary logistic regression of GPs planning to retire or leave GP (see online supplementary file 2) identified those aged between 55-59years and 60-64years were much more likely to express an intention to leave, when compared with those aged 25-34 (OR 7.98; 95\% CI 2.6 to $24.1 ; \mathrm{p}<0.001$, OR $7.1 ; 95 \%$ CI 1.7 to 30.0 ; $\mathrm{p}<0.01$, respectively). Likewise, those who have served 20-29years in GP were more likely to express an intention to leave when compared with those with less than 5 years of service (OR 3.3; 95\% CI 1.3 to 8.3; $<<0.05$ ). Lower job satisfaction over the past 2 years was also significantly associated with intention to leave (OR 4.2; 95\% CI 2.3 to $7.6 ; \mathrm{p}<0.001$ ).

A further regression, controlling for age and gender (see online supplementary file 2), showed that there was a modest association between having reduced working hours over the past 2 years and an intention to leave GP completely (OR 1.595; 95\% CI 1.062 to 2.397 , $\mathrm{p}<0.05$ ).

Respondents were asked to rate on a Likert scale ( $1=$ not important, $5=$ very important $)$ factors that might be contributing to their intention to leave GP (table 4). Intensity of workload had the greatest influence (mean=4.4) followed closely by volume of workload (mean $=4.3)$ and too much time spent on unimportant tasks (mean=4.0). Lack of patient contact, potential introduction of a 7-day working week and reduced job satisfaction also scored a mean $>3$. Personal factors of note were age (mean=3.5), medical indemnity payments (3.4) and increased risk of litigation (3.0). They were also asked to rate factors that might help retain them in GP (table 4), again confirming the importance of addressing the volume and intensity of workload. 
Table 4 Factors influencing intention to leave or remain working in general practice (GP)

\section{Factors influencing decision to leave GP (1=not important to $5=$ very important)}

Factors that might retain GPs in practice (1=not important to $5=$ very important)

\begin{tabular}{|c|c|c|c|c|c|c|c|}
\hline & $\mathbf{N}$ & Mean & SD & & $\mathbf{N}$ & Mean & SD \\
\hline Intensity of workload & 113 & 4.4 & 1.0 & Reduced intensity of workload & 109 & 4.1 & 1.4 \\
\hline Volume of workload & 114 & 4.3 & 1.0 & $\begin{array}{l}\text { Longer appointment times/more time to } \\
\text { spend with patients }\end{array}$ & 109 & 4.0 & 1.4 \\
\hline $\begin{array}{l}\text { Too much time spent on } \\
\text { unimportant tasks }\end{array}$ & 113 & 4.0 & 1.2 & Reduced volume of workload & 110 & 3.9 & 1.4 \\
\hline Lack of time for patient contact & 113 & 3.8 & 1.2 & Less administration & 108 & 3.9 & 1.4 \\
\hline $\begin{array}{l}\text { Potential introduction of } 7 \text { days a } \\
\text { week working }\end{array}$ & 113 & 3.8 & 1.4 & No out of hours commitments & 109 & 3.6 & 1.6 \\
\hline Reduced job satisfaction & 110 & 3.6 & 1.3 & Incentive payment & 108 & 3.5 & 1.5 \\
\hline Poor flexibility of hours & 108 & 2.8 & 1.4 & Protected time for education and training & 107 & 3.3 & 1.4 \\
\hline \multirow[t]{2}{*}{ Revalidation } & 112 & 2.6 & 1.5 & More flexible working conditions & 106 & 3.2 & 1.5 \\
\hline & & & & Greater clinical autonomy & 107 & 3.0 & 1.5 \\
\hline Age & 113 & 3.5 & 1.3 & Increased pay & 107 & 2.9 & 1.4 \\
\hline Medical indemnity payments & 113 & 3.4 & 1.4 & Improved skill mix in the practice & 106 & 2.8 & 1.4 \\
\hline Increased risk of litigation & 111 & 3.0 & 1.5 & Additional annual leave & 107 & 2.8 & 1.5 \\
\hline Changes to pension taxation & 112 & 2.7 & 1.5 & Shorter practice opening times & 108 & 2.7 & 1.5 \\
\hline Family commitments & 111 & 2.6 & 1.2 & Opportunity for a sabbatical & 107 & 2.6 & 1.5 \\
\hline III health & 109 & 1.8 & 1.2 & Introduction of 'Twenty Plus' & 106 & 2.3 & 1.3 \\
\hline $\begin{array}{l}\text { Embarking on career outside } \\
\text { general practice }\end{array}$ & 109 & 1.6 & 0.98 & Expansion of GP retainer scheme & 105 & 2.1 & 1.4 \\
\hline \multirow[t]{3}{*}{ Planned career break } & 107 & 1.4 & 0.89 & $\begin{array}{l}\text { Extended interests; for example, Clinical } \\
\text { Commissioning Group (CCG) role }\end{array}$ & 106 & 2.0 & 1.3 \\
\hline & & & & $\begin{array}{l}\text { Reintroduction of the flexible careers } \\
\text { scheme }\end{array}$ & 105 & 2.0 & 1.2 \\
\hline & & & & Option to work term time only & 105 & 1.6 & 1.1 \\
\hline
\end{tabular}

\section{Current challenges to general practice}

Analysis of the responses to the open question 'What is the greatest problem within general practice at the current time?' yielded five key themes: increasing demands, expectations and complexity of patients; workload; GP recruitment and retention; inadequate funding; and bureaucratic and administrative burden.

Increasing demands, expectations and complexity of patients $40.7 \% \quad(\mathrm{n}=333)$ expressed a view that the increasing demands and complexity of patients are one of the greatest problems facing general practice. Participants highlighted how there are insufficient numbers of GPs or sufficient health service resources to meet this rise in expectations and demands. Several felt that the increase in demands and expectations has been driven by the media and government.

Increasing patient demands with limited time \& resources to manage this (ID 403)

Unrealistic patient expectations fuelled by politicians and media (ID 814)
Demands and expectations are rising at the same time as life expectancy, chronic health conditions and multimorbidity. Therefore, many patients require more input from their GP.

Patients demands are more difficult and complex due to people living longer with more chronic diseases for example, Diabetes, COPD, CHD, Renal failure, Dementia, Mental health problems, hypertension and many more (ID 510)

Workload

The high volume and intensity of work was highlighted by many $(32.0 \%, \mathrm{n}=262)$, and described as 'ever-increasing' and 'unsustainable' leading to stress and exhaustion.

Hugely stressed and exhausted workforce working at or above maximum capacity both individually and as workplace units (ID 556)

GP recruitment and retention

$30.2 \% \quad(\mathrm{n}=247)$ highlighted about difficulties that included recruiting experienced GPs to fill vacant posts, 
attracting doctors into GP training and encouraging GPs to become partners. These workforce issues have been compounded by GPs retiring, reducing their hours or taking on alternative duties such as working with Clinical Commissioning Groups (CCGs).

...awful recruitment. Most GPs can't see a good future for their practice - it should be one of the best jobs there is (ID 415)

\section{Inadequate funding}

Inadequate funding was highlighted by $19.66 \%$ ( $\mathrm{n}=161)$. Participants described not being able to properly fund the services and staff to meet patient's needs. Several also stated that the financial rewards involved in general practice were not keeping up with the increasing complexity, workload and risk involved with the job.

I feel that there is not enough money available to provide the services that patient require and deserve (ID 511)

At the same time as the complexity, intensity and perceived risk of continuing to work is increasing there is little or financial or other reward to offset it (ID 819)

\section{Bureaucratic and administrative burden}

Participants described how additional bureaucratic and administrative tasks take time away from looking after patients and performing their clinical role, further adding to their workload. This includes time meeting the requirements imposed on them by regulatory and commissioning organisations, as well as the duties and paperwork that need to be completed for quality payments, appraisals and hospital colleagues.

Excessive bureaucracy that is, CQC, CCG, NHS England, appraisal. We are grossly over managed, this prevents us seeing patients or developing services for our patients and employs an army of managers (some clinical) (ID 902)

\section{Suggestions for improving general practice}

Responses to the open question 'What intervention would help general practice the most?' revealed eight themes. The number of respondents with answers that included each theme is shown in table 5 .

\section{Greater funding}

Increasing funding for general practice was viewed as the most important requirement. Many participants felt that other problems, such as the lack of GPs and meeting patients' expectations, could only be tackled with greater funding.

It's all money. More money to pay extra GPs and pay GPs more to attract good doctors and retain the drs once trained (ID 220)
Table 5 Interventions that were suggested by respondents as being most relevant to improving general practice

\begin{tabular}{lll}
\hline Improvement measure & $\begin{array}{l}\text { No of } \\
\text { respondents }\end{array}$ & $\begin{array}{l}\text { Percentage of } \\
\text { respondents (\%) }\end{array}$ \\
\hline Greater funding & 225 & 27.9 \\
\hline More GPs & 184 & 22.8 \\
\hline Educate patients and the public & 107 & 13.3 \\
\hline Increase clinical and support staff & 92 & 11.4 \\
\hline $\begin{array}{l}\text { Reduce bureaucracy and } \\
\text { administration }\end{array}$ & 91 & 11.3 \\
\hline More time per patient & 65 & 8.2 \\
\hline Reduced workload & 56 & 6.9 \\
\hline Protection from financial risk & 48 & 6.0 \\
\hline Enhanced reputation & 44 & 5.5 \\
\hline
\end{tabular}

\section{More GPs}

Increasing the number of GPs would lead to both better patient care and an improved work-life balance. The current imbalance was seen as creating a self-perpetuating cycle where fewer GPs means more workload for each remaining GP, so making the profession less popular for new entrants.

'One young GP would stabilise my practice and reduce the risk of closure' (ID 461)

\section{Educate patients and the public}

To reduce excessive demands and expectations, patients should be made aware of the costs and limitations of primary care. There should also be increased health education for patients so that they can better self-manage their own health. However, it was not clear how such interventions should be delivered.

Patient education for self limiting illness Patient education to reduce expectation Patient education to reduce chronic disease. (ID 81)

\section{Increase clinical and support staff}

As well as more GPs, an increase in non-medical clinical and support staff was highlighted as essential. Several participants expressed the view that an expanded role for these staff would allow GPs to focus on more complex medical issues which they are trained to deal with.

Funding for ancillary staff to see more of the routine stuff enable GPs to do chronic disease management, EOL (end of life) and complexity that they deal with best (ID 444)

\section{Reduce bureaucracy and administration}

Spending less time on administrative tasks and more time on their clinical role would allow patient care and job satisfaction to improve. It was felt that this could also be achieved quickly compared with the time needed to train and recruit new GPs. 
Reduction in administration-we can't do anything about patient demand, other than train more GPs, which takes a great deal of time. A third of my time is spent on administration, a lot of which is reading through unnecessarily duplicated reports and results, extraneous information from hospitals, or acting as a secretary with a prescribing licence for hospital colleagues. (ID 669)

\section{More time per patient}

Longer appointments are needed to address the complex needs of patients, but it was recognised that this might have the perverse consequence of increasing hours of work and/or reducing salary.

....ability to have longer appointments to provide proper holistic care (ID 384).

...Increase consultation length without increasing working hours or reduced remuneration (ID 106).

\section{Protection from financial risk}

Many participants felt that a big detraction from working as a GP was the financial risk involved and the cost of covering that risk in indemnity fees. It was felt that this affected the extent to which doctors choose to work in general practice, and forces others to retire or reduce their hours. This was seen as something that the NHS should address.

Government or CCG paying our indemnity. This would then allow GPs to work more sessions without a negative financial return. Salaried GPs could also be better paid as a result. If our indemnity is not covered by some outside body in the next few years general practice will completely collapse as, even in its current state, it is unaffordable. Year on year rises of $15 \%-20 \%$ are not sustainable (ID 193)

\section{Enhanced reputation of general practice}

Several participants mentioned that improving the image of general practice was vital to address the problems that it faced.

Improved public image thereby improving recruitment (ID802)

Substantial boost to go finance and boost to perception of GP's at medical school (ID225).

\section{Positivity towards, awareness and experience of national workforce initiatives}

Respondents were asked to rate whether they thought about the nationally led initiatives that had been recently introduced to address workforce issues in general practice, specifically whether the initiatives would have a positive, negative or no impact. A net rating was calculated by subtracting the percentage who rated the initiative as negative from the percentage who rated it as a positive. As shown in table 6, investment in practice nursing, improved access to specialist advice, investment in technology and expansion of the GP workforce were viewed most favourably, with greater than $75 \%$ net rating scores. Conversely, the wider use of physician associates (PAs), local sustainability and transformation plans (STPs), and

Table 6 Net rating (positivity), awareness of and experience of initiatives intended to address workforce issues in general practice

\begin{tabular}{llll} 
Initiative & $\begin{array}{l}\text { Net rating of } \\
\text { initiative (\%) }\end{array}$ & $\begin{array}{l}\text { Awareness of } \\
\text { initiative }\end{array}$ & $\begin{array}{l}\text { Experience of } \\
\text { initiative }\end{array}$ \\
\hline Investment in practice nursing & +91.3 & $39.7 \%(288)$ & $19.2 \%(104)$ \\
\hline Closer working with specialists; for example, phone and email advice lines & +85.3 & $73.3 \%(537)$ & $55.1 \%(343)$ \\
\hline Investment in technology & +85.3 & $52.2 \%(375)$ & $30.9 \%(170)$ \\
\hline Expansion of GP workforce & +76.1 & $81.7 \%(612)$ & $15.0 \%(94)$ \\
\hline Streamlining CQC, reduced inspection for good and outstanding practices & +73.1 & $51.4 \%(375)$ & $17.6 \%(98)$ \\
\hline Investment in primary care infrastructure & +70.3 & $45.0 \%(318)$ & $20.0 \%(105)$ \\
\hline Releasing time for patients & +60.6 & $26.4 \%(193)$ & $13.1 \%(62)$ \\
\hline Increased use of pharmacists & +56.2 & $96.9 \%(738)$ & $56.1 \%(404)$ \\
\hline Paramedics in primary care & +44.5 & $86.4 \%(652)$ & $34.9 \%(239)$ \\
\hline Practice resilience programme & +41.2 & $57.3 \%(415)$ & $27.8 \%(153)$ \\
\hline Multispecialty community provider projects & +25.3 & $53.5 \%(382)$ & $27.0 \%(143)$ \\
\hline Federation of GP practices & +19.3 & $92.7 \%(707)$ & $53.7 \%(369)$ \\
\hline Better care fund & +13.2 & $37.6 \%(278)$ & $26.8 \%(130)$ \\
\hline Physicians associates & -0.2 & $78.5 \%(589)$ & $8.1 \%(54)$ \\
\hline Local sustainability and transformation plans & -21.3 & $80.7 \%(606)$ & $42.2 \%(268)$ \\
\hline Video and e-consultations & -26.6 & $80.4 \%(597)$ & $33.4 \%(233)$ \\
\hline
\end{tabular}

CQC, Care Quality Commission. 


\begin{tabular}{|c|c|c|}
\hline Initiative & $\mathbf{r}$ & $P$ value \\
\hline Federation of GP practices & -0.151 & $<0.001^{*}$ \\
\hline $\begin{array}{l}\text { Local sustainability and transformation } \\
\text { plans }\end{array}$ & -0.060 & 0.151 \\
\hline Increased use of pharmacists & -0.088 & $0.024^{*}$ \\
\hline Physicians associates & 0.136 & $0.001^{*}$ \\
\hline Paramedics in primary care & -0.089 & $0.029^{\star}$ \\
\hline Better care fund & 0.007 & 0.884 \\
\hline Expansion of GP workforce & -0.012 & 0.782 \\
\hline Video and e-consultations & 0.071 & 0.087 \\
\hline Releasing time for patients & -0.108 & $0.032^{*}$ \\
\hline Practice resilience programme & -0.070 & 0.129 \\
\hline $\begin{array}{l}\text { Streamlining CQC, reduced inspection } \\
\text { for good and outstanding practices }\end{array}$ & 0.000 & 0.992 \\
\hline Investment in practice nursing & -0.006 & 0.899 \\
\hline $\begin{array}{l}\text { Closer working with specialists; for } \\
\text { example, phone and email advice lines }\end{array}$ & -0.072 & 0.084 \\
\hline Investment in technology & -0.079 & 0.082 \\
\hline Investment in primary care infrastructure & -0.024 & 0.599 \\
\hline $\begin{array}{l}\text { Multispecialty community provider } \\
\text { projects }\end{array}$ & -0.095 & $0.040^{*}$ \\
\hline
\end{tabular}

${ }^{*} \mathrm{P}<0.05$, r: Spearman's rank correlation coefficient. $r>0$ denotes positivity increasing with age; $r<0$ denotes positivity decreasing with increasing age.

GP, general practice; CQC, Care Quality Commission.

video and e-consultations were rated negatively. There were mixed levels of awareness about the various national workforce initiatives being implemented, and with few exceptions (closing working with specialists, increased use of pharmacists, involvement in GP federations) the majority of respondents lacked direct experience of them (table 6).

Age emerged as having a small, but statistically significant correlation with attitude towards several individual initiatives (table 7). For example, younger GPs were more likely to be positive about federations, but were less positive in their views of PA. However, the attitudes towards most of the initiatives were very similar across all age groups.

Having had experience of an initiative was associated with a more positive attitude score towards it. The differences in mean scores were modest, but for seven of the initiatives, the difference was statistically significant (table 8).

One hundred and ninety GPs gave free-text comments to explain their views. The most widely stated theme was that there were too many initiatives, of which little or no benefit was being seen on the ground.

There are too many initiatives. GPs just need to be left alone to get on with the job with adequate funding.
These initiatives cost money which comes out of GP budgets ID 925

Many of these ideas are great on paper but little evidence of impact at the coalface ID 826

Many felt that these initiatives were a distraction from the need for significant investment in general practice and tackling key issues affecting the workforce.

The only thing that will make any real improvement in care is investment in proper well-trained GPs continuing to be the centre of patient care in primary care alongside practice nurses with a proper career structure and practice pharmacists. All the other initiatives are just tinkering at the edges - smokescreens to try to take the heat off the central issue of lack of investment in General Practitioners ID 688

An additional theme suggested that some initiatives could be further undermining GP morale.

I object to the term 'resilience' and any resources invested into it. We should be focusing all our intentions on making the job better rather than coaching GPs to be more robust against the stress. The very term makes it sound to me like it is somehow the GPs fault in the first place for not coping with the stains and demands of the job. ID 569

\section{DISCUSSION}

\section{A worsening situation}

This survey describes a picture of increasing workload, falling morale and an accelerating workforce crisis. Since the initial survey in $2014,{ }^{16}$ GPs' stated intention to retire in the next 2 years has increased significantly with $48.5 \%$ of respondents to the current survey stating that they planned to leave working in GP sooner than they had expected 2 years ago. A majority reported an increase in hours of work since the previous survey, reflecting increasing workload, despite only $2.7 \%$ having expressed a wish to increase hours in the previous survey. Almost all $(97.5 \%)$ were experiencing increasing appointment numbers to meet patient demand and $69.0 \%$ to manage patient complexity. The number of GPs planning a reduction in clinical hours has also increased. Many GPs are working over 40 hours a week and some up to 70, and most reported a reduction in morale and job satisfaction. In general, GP principals reported working substantially longer hours than salaried GPs or locums. These findings are in line with national findings of increasing consultation rates, length and clinical workload. ${ }^{18}$

The reasons given for intending to leave are similar to those described in earlier surveys. ${ }^{7810-1319}$ Workload remains the dominant driver to leave. Respondents who described having recently reduced their hours of work were more likely to express an intention to leave than others, suggesting intentions are affected by the nature and intensity of the work, together with other factors such 
Table 8 Comparison between previous experience of initiative and attitude to initiative

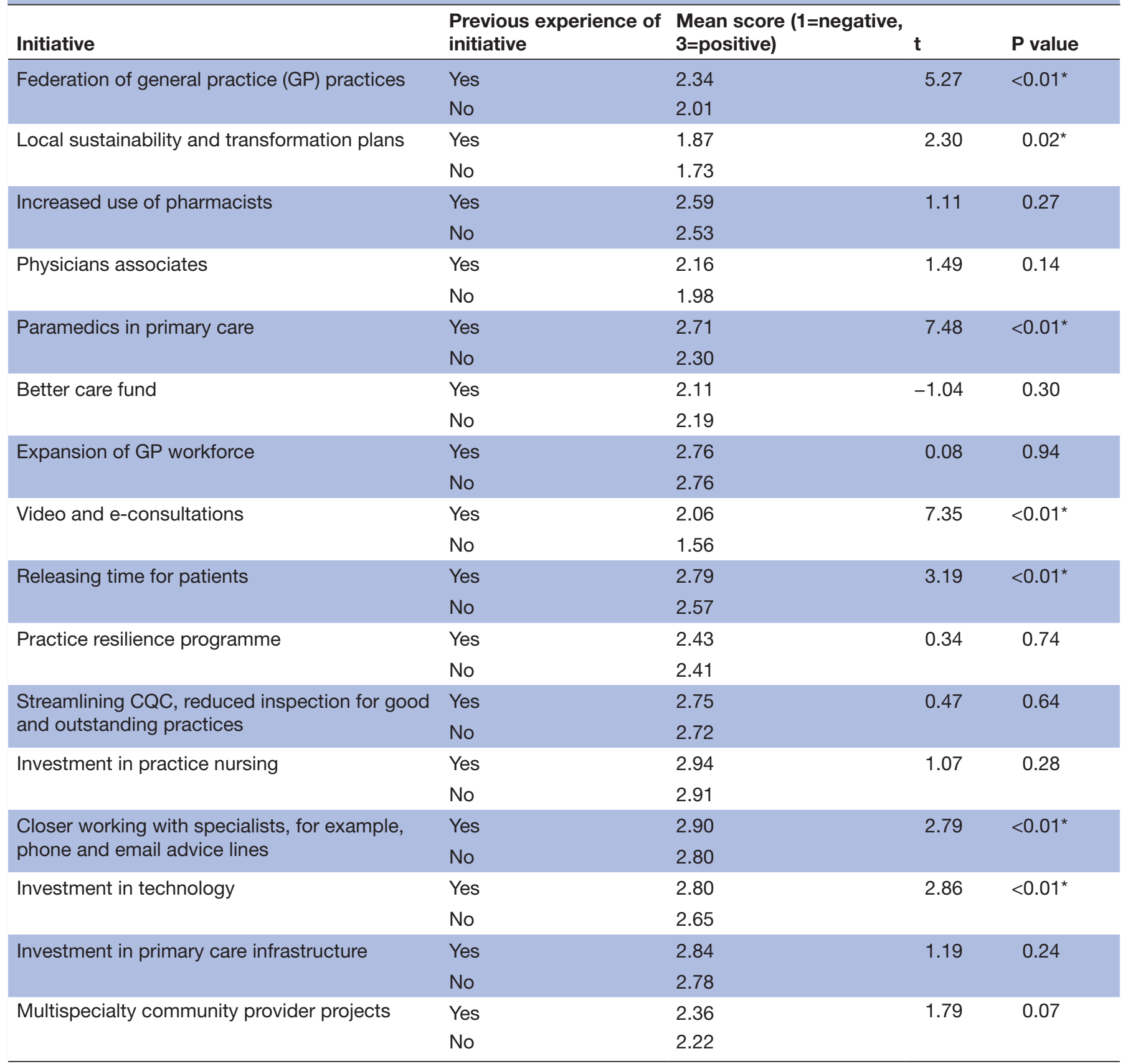

${ }^{*} \mathrm{p}<0.05$.

CQC, Care Quality Commission.

as morale and job satisfaction, rather than by the number of hours alone. Given that one of the main reasons why doctors choose careers in GP is in order to have a better work-life balance, ${ }^{20}$ this increasing workload may result in disillusionment, low morale and be contributing to the increasing number of GPs choosing to work as non-principals and working fewer sessions from early in their careers. ${ }^{9}$

The survey was commissioned in part to discover whether the findings in Dale et $a l^{21}$ about the negative impact of appraisal and revalidation on the retention of GPs in the West Midlands was replicated in Wessex. The
Appraisal Service is unique in NHS England in being directly commissioned from an educationally based provider and has a conscious ethos of trying to facilitate appraisals with a strong emphasis on the support of the individual doctor. Although revalidation was reported as a minor factor in the intention to leave clinical work, appraisal itself did not emerge as a demonstrable factor.

The study identified that GPs vary in their enthusiasm for, awareness of, and experience of, national initiatives that are aimed at addressing workforce issues. Investment in practice nursing, closer working with specialists (eg, phone and email advice lines), investment in technology 
and expansion of the GP workforce were the initiatives that were viewed as being likely to have greatest positive impact. However, there was a widespread view that there were too many initiatives and that these were often complex to access; they would prefer for the investment to go directly to practices to decide how best to support their working practices. Despite this, the response to individual initiatives is mostly positive, with the exception of PAs, video and e-consultations and STPs. GPs who had experience of an initiative tended to view it more positively than others, suggesting that familiarity may lead to GPs becoming more aware of, and perhaps less sceptical, of their potential benefits.

The negative response to PAs in somewhat surprising in the context of the positive responses to increased numbers of nurses, pharmacists and paramedics working in primary care. PA training programmes are becoming increasingly in number across the NHS, and hence there may be a need to manage expectations for this workforce, as previously described ${ }^{22}$ despite evidence to suggest they are well received by patients. ${ }^{23}{ }^{24}$ The Roland report ${ }^{14}$ viewed multidisciplinarity as one of the key solutions to sustaining primary care, though concerns have been raised about loss of continuity of care ${ }^{16}$ and resultant reduction in patient satisfaction. ${ }^{25}$ Future GP roles within increasingly diverse teams may need redefining and there has been interesting in alternative models of care,${ }^{26} \mathrm{such}$ as the Nuka system in Alaska. ${ }^{27}$

The strongest negative response was to STPs. Considering these are the main vehicle by which the 5-year forward plan for GP is being driven and support closer working between health and social care, ${ }^{28}$ that so many GPs believe they may make things worse is of concern. Further research in this area would be beneficial to understanding why many GPs lack confidence in this area, and what may be needed to promote greater positivity.

While investment in technology was positively received, e-consulting and video consulting were perceived negatively. Pilot studies have suggested that e-consulting may increase workload and costs as well as reducing patient satisfaction. ${ }^{29-31}$

Expansion of the general practice workforce remains a high priority to GPs. This has been recognised as an issue at governmental level, however, the response of increasing medical student numbers will not start to impact until 2028 at the earliest. ${ }^{32}$ An International GP recruitment programme has been set up, ${ }^{33}$ initially targeting GPs from the European Economic Area; however, there are concerns that uncertainties surrounding Brexit have impact on its success, and may result in EEA GPs currently working in the UK returning home. ${ }^{34}$

Perhaps the most interesting aspect of the survey was GPs' views on what would improve general practice. More funding was the strongest theme, particularly for increasing the size of the workforce, both of GPs and other health professionals. This would enable a more manageable and sustainable workload, including longer appointments, so helping to reduce the risk of burn-out. ${ }^{35}$
Increasing financial demands including rising indemnity payments were also of concern, and there was enthusiasm for a national indemnity scheme. Reducing bureaucracy was identified, but less strongly than in previous surveys, ${ }^{9}$ possibly reflecting the reduction in incentive-related workstreams, the clinical value of which is now questioned. ${ }^{36}$ It is possible that the negative response to STPs relates to increased perceived bureaucracy. A number of innovative, more strategic suggestions emerged which may be worthy of further consideration.

\section{Strengths and limitations}

This study provides further evidence of the unfolding GP workforce crisis in England. A particular strength is that it demonstrates how attitudes are changing over recent years. However, the extent to which the findings could be compared with the earlier survey was limited due to privacy restrictions. There were some differences in characteristics between the two surveys (eg, respondents to the current survey were slightly older and were less likely to be GP principals) which need to be considered when interpreting comparisons. However, the difference in age profile was insufficient to account for the shift towards seeking earlier retirement.

The survey's focus on how the crisis might be addressed is a strength, with the study providing evidence of the impact that national initiatives are felt to be having. The response rate was good for this type of survey; the questionnaire was quite lengthy and there was no incentive to support participation. The extent to which participants wrote free-text comments reflects the importance placed on this topic by GPs and added significant depth to the findings. However, it is likely that those who feel most strongly about their workloads either might have selectively responded to the questionnaire, or alternatively felt too busy and stressed to add completing a survey to their workload. Though this is in inevitable with this sort of study, it is a limitation in terms of drawing conclusions from the quantitative findings. While the findings are limited to a single region in England, they are reflective of views that have been expressed in other recent GP surveys and so are likely to have applicability across the NHS.

\section{CONCLUSION}

The role of the GP has changed significantly and rapidly over the past 20 years and initiatives to manage these changes have often been short-lived and reactive in approach, without sufficient evidence to support them or engagement with grass roots GPs. Perhaps now is the time to reflect more broadly on what the practice of future GPs will encompass and how a new generation of GPs can be trained to prepare for this. New models of care and the relationships and roles of different healthcare professionals need to be considered. The debate needs to include the public; what do they want from a primary care system and what can be afforded without substantially more funding. Given the scale of the crisis, increased 
funding needs to be directed to ensure the effects are widely experienced across front-line general practice. Without fundamental change, it is hard to foresee the current workforce decline reversing.

Acknowledgements We are grateful to Dr Susi Caesar (Associate Dean, Wessex Appraisal Service Lead, Health Education England) for her advice regarding the study design and for commenting on drafts of the manuscript.

Contributors $\mathrm{KO}$ and JD designed the study; TS and TH undertook data analysis, supervised by $\mathrm{KO}$; all authors contributed to the interpretation of findings and the drafting of the paper.

Funding This work was supported by a grant from Health Education England Wessex Appraisal Service.

Competing interests None declared.

Patient consent for publication Not required.

Ethics approval The Biological Sciences Research Ethics Committee of the University of Warwick reviewed and approved the study (REG0-2017-2032).

Provenance and peer review Not commissioned; externally peer reviewed.

Data sharing statement The data are stored at the Unit of Academic Primary Care, Warwick Medical School, University of Warwick. KO is responsible for the data, which are all anonymised.

Open access This is an open access article distributed in accordance with the Creative Commons Attribution Non Commercial (CC BY-NC 4.0) license, which permits others to distribute, remix, adapt, build upon this work non-commercially, and license their derivative works on different terms, provided the original work is properly cited, appropriate credit is given, any changes made indicated, and the use is non-commercial. See: http://creativecommons.org/licenses/by-nc/4.0/.

\section{REFERENCES}

1. Dayan M, Arora S, Rosen R, et al. Is general practice in crisis? 2014 https://www.nuffieldtrust.org.uk/files/2017-01/general-practice-incrisis-web-final.pdf (Accessed 31st Jul 17).

2. Baird B. Is general practice in crisis?: The_kings_fund. $2017 \mathrm{https}: / /$ www.kingsfund.org.uk/publications/articles/big-election-questionsgp-crisis (Accessed 18th Nov 17).

3. Roland $\mathrm{M}$, Everington $\mathrm{S}$. Tackling the crisis in general practice. BMJ 2016;352:i942-3.

4. England NHS, England HE, et al. Building the workforce: the new deal for general practice. 2015 26.1.2015. http://www.england.nhs. $\mathrm{uk} /$ commissioning/wp-content/uploads/sites/12/2015/01/buildingthe-workforce-new-deal-gp.pdf (Accessed 21st Feb 2018).

5. Digital NHS. General and personal medical services, England, As at 30 September 2017: Provisional Experimental Statistics, 2017.

6. Marchand C, Peckham S. Addressing the crisis of GP recruitment and retention: a systematic review. Br J Gen Pract 2017;67:e227-37.

7. Fletcher E, Abel GA, Anderson R, et al. Quitting patient care and career break intentions among general practitioners in South West England: findings of a census survey of general practitioners. BMJ Open 2017;7:e015853.

8. Dale J, Potter R, Owen K, et al. Retaining the general practitioner workforce in England: what matters to GPs? A cross-sectional study. BMC Fam Pract 2015;16:140-51.

9. Dale J, Russell R, Scott E, et al. Factors influencing career intentions on completion of general practice vocational training in England: a cross-sectional study. BMJ Open 2017;7:e017143.

10. Sansom A, Terry R, Fletcher E, et al. Why do GPs leave direct patient care and what might help to retain them? A qualitative study of GPs in South West England. BMJ Open 2018:8:e019849.

11. Sansom A, Calitri R, Carter M, et al. Understanding quit decisions in primary care: a qualitative study of older GPs. BMJ Open 2016;6:e010592.

12. Doran N, Fox F, Rodham K, et al. Lost to the NHS: a mixed methods study of why GPs leave practice early in England. Br J Gen Pract 2016;66:e128-35.
13. Croxson $\mathrm{CH}$, Ashdown HF, Hobbs FR. GPs' perceptions of workload in England: a qualitative interview study. Br J Gen Pract 2017;67:e138-47.

14. Primary Care Workforce Commission. The future of primary care: creating teams for tomorrow. 2015

15. Nelson P, Martindale AM, McBride A, et al. Skill-mix change and the general practice workforce challenge. Br J Gen Pract 2018:68:66-7.

16. LMCs W. GP Recruitment Crisis. 2014 https://www.wessexlmcs. com/gprecruitmentcrisis

17. Ritchie J, Spence L. Qualitative data analysis for applied policy research. London, Routledge: Analysing Qualitative Data, 1994.

18. Hobbs FDR, Bankhead C, Mukhtar T, et al. Clinical workload in UK primary care: a retrospective analysis of 100 million consultations in England, 2007-14. Lancet 2016;387:2323-30.

19. Hann M, Reeves D, Sibbald B. Relationships between job satisfaction, intentions to leave family practice and actually leaving among family physicians in England. Eur J Public Health 2011;21:499-503.

20. Jones L, Fisher T. Workforce trends in general practice in the UK: results from a longitudinal study of doctors' careers. Br J Gen Pract 2006;56:134-6.

21. Dale J, Potter R, Owen K, et al. The general practitioner workforce crisis in England: a qualitative study of how appraisal and revalidation are contributing to intentions to leave practice. $B M C$ Fam Pract 2016;17:84.

22. Jackson B, Marshall M, Schofield S. Barriers and facilitators to integration of physician associates into the general practice workforce: a grounded theory approach. Br J Gen Pract 2017:67:e785-91.

23. Halter M, Drennan VM, Joly LM, et al. Patients' experiences of consultations with physician associates in primary care in england: a qualitative study. Health Expect 2017;20:1011-9.

24. Drennan VM, Halter M, Joly L, et al. Physician associates and GPs in primary care: a comparison. Br J Gen Pract 2015;65:e344-50.

25. Hjortdahl $P$, Laerum E. Continuity of care in general practice: effect on patient satisfaction. BMJ 1992;304:1287-90.

26. The Kings Fund. Innovative models of care delivery in general practice. $2017 \mathrm{https} / / / \mathrm{www}$. kingsfund.org.uk/projects/innovativemodels-care-delivery-general-practice (Accessed 22nd Feb 18).

27. The Kings Fund. Nuka system of care, Alaska. 2015 https://www. kingsfund.org.uk/publications/population-health-systems/nukasystem-care-alaska (Accessed 19th Mar 18).

28. England NHS. Delivering the forward view: NHS planning guidance. 2015.

29. Edwards HB, Marques E, Hollingworth W, et al. Use of a primary care online consultation system, by whom, when and why: evaluation of a pilot observational study in 36 general practices in South West England. BMJ Open 2017;7:e016901.

30. Farr M, Banks J, Edwards HB, et al. Implementing online consultations in primary care: a mixed-method evaluation extending normalisation process theory through service co-production. BMJ Open 2018;8:e019966

31. Banks J, Farr M, Salisbury C, et al. Use of an electronic consultation system in primary care: a qualitative interview study. $\mathrm{Br} J$ Gen Pract 2018;68:e1-8.

32. Department, of, Health, et al. 1,500 extra medical undergraduate places confirmed. 2017 https://www.gov.uk/government/news/1500extra-medical-undergraduate-places-confirmed (Accessed 22nd Feb 18).

33. NHS England. International GP recruitment programme. $2017 \mathrm{https}: / /$ www.england.nhs.uk/gp/gpfv/workforce/building-the-generalpractice-workforce/international-gp-recruitment/ (Accessed 22nd Feb 18).

34. Esmail A, Panagioti M, Kontopantelis E. The potential impact of Brexit and immigration policies on the GP workforce in England: a cross-sectional observational study of GP qualification region and the characteristics of the areas and population they served in September 2016. BMC Med 2017;15:191.

35. Irving G, Neves AL, Dambha-Miller $\mathrm{H}$, et al. International variations in primary care physician consultation time: a systematic review of 67 countries. BMJ Open 2017;7:e017902.

36. Forbes L, Marchand C, Peckham S. Review of the quality and outcomes framework in England. 2016 http://blogs.Ishtm.ac. uk/prucomm/2017/02/07/review-of-the-quality-and-outcomesframework-in-england/ (Accessed 22nd Feb 18). 